\title{
O DISPOSITIVO DE MEMÓRIA DE ALDO BECK
}

The Aldo Beck memory device

Francine Regis Goudel ${ }^{1}$ 


\section{Resumo}

Através da leitura da obra "Vista da cidade" de 1970, do artista catarinense Aldo Beck, o presente texto pretende analisar os aspectos visuais, contextuais e semânticos que circundam a obra em questão. Tomando como base de sua poética a representação da paisagem e utilizando-se de alguns artifícios considerados "contemporâneos", Aldo Beck colaborou para a construção da memória visual de sua cidade natal, Florianópolis, e nos possibilitou olhar para sua obra a partir de novas interlocuções de saber.

Palavras-Chave: Aldo Beck, Florianópolis, Pintura de Paisagem, Memória, Apropriação.

\section{Abstract}

Through the reading of the work "View of the city", by southern Brazil artist Aldo Beck, from 1970, this paper intends to analyze the visual, contextual and semantic aspects surrounding the work in question. On the basis of his poetic representation of the landscape and using some mechanism considered "contemporary", Aldo Beck contributed to the construction of the visual memory of his hometown, Florianopolis, and allowed us to look at his work considering new perspectives.

Palavras-Chave: Aldo Beck, Florianópolis, Landscape Painting, Memory, Appropriation .

ISSN: 1808-3129

\footnotetext{
1 Doutoranda em Artes Visuais na linha de Pesquisa Teoria e História das Artes Visuais pelo PPGAV do Centro de Artes da Universidade do Estado de Santa Catarina - UDESC, mestre em Estudos Avançados em História da Arte pela Faculdade de Geografia e História da Universidade de Barcelona - UB, Espanha, pós-graduada em Gestão Cultural pela Faculdade de Ciências Econômicas da Universidade Nacional de Córdoba - UNC, Argentina e graduada em Licenciatura em Educação Artística, com habilitação em Artes Plásticas pelo Centro de Artes da UDESC. Atualmente dirige a Lugar Específico, uma plataforma especializada em serviços para Artistas Visuais e Circuito de Arte Contemporânea, é Coordenadora da Agenda Cultural e Programa de Residência Artística do Espaço Cultural Armazém - Coletivo Elza, em Florianópolis, Santa Catarina e Diretora Executiva do PRAC\#3 - Programa de Residência Artística da Casinha\#3, em São Paulo, capital.

PPGAV/UDESC - Lugar Específico

francinegoudel@gmail.com
} 


\section{Introdução}

Aos olhos do bom florianopolitano, as pinturas de paisagens de Aldo Beck fazem referência explícita à imanência da cidade. Pertencem ao campo do deleite visual de uma inexplicável essência, que remonta uma história por vezes nem praticada, mas que engendra todo o sentido de pertencimento ao local. São imagens que muitas vezes reconstituem a arquitetura e costumes locais de um tempo remoto, distante incluso do próprio artista que pintou sua terra natal em um momento ido, como uma tentativa de capturar a atmosfera do que havia passado, retomar um local inexistente, materializar uma vontade de não-progresso, uma vontade de memória.

Aldo Beck, natural de Florianópolis (1919-1999), realizou a produção destas paisagens entre os anos de 1949 e 1998. Autodidata, exímio no desenho de observação, incentivado a pintar quando ainda menino pelo então amigo da família e relevante artista catarinense Eduardo Dias ${ }^{1}$, realizou aproximadamente 45 exposições ao longo de sua atuação artística. (BECK, s.d.; NEVES, 1968)

Enquanto o cenário artístico mundial despontava obras de arte transcendentes como a Pop Arte, o conceitualismo e até mesmo no Brasil o concretismo e neoconcretismo, o panorama de Aldo Beck em Florianópolis parecia apontar em direção a outra contemporaneidade. Tomou como base de sua poética a representação da paisagem e como força motriz de suas imagens a essência de uma capital catarinense de final do século XIX. Porém, ele não estava só nesta direção. Como Aldo Beck, alguns de seus contemporâneos beberam da influência dessa representação pictórica, como Martinho de Haro, Aldo Nunes, José Silveira D'Ávila, Domingos Fossari, entre outros. Até mesmo em expressivas obras modernas de artistas como Valda Costa, Hassis ou Willy Zumblick podemos encontrar toda a imagética saudosa pairando no imaginário artístico, como pano de fundo para um personagem ou em certo grau de abstração, a geração artística moderna na capital desterrense foi insuflada de um imaginário paisagístico. (BORTOLIN, 2002. LEHMKUL, 1996. MAKOWIECKY; CHEREM, 2010).

O projeto modernista na capital catarinense também apresentou, como em certa medida a nível nacional, questões de retorno a cultura raiz e imersão nos costumes locais. Entretanto, em Florianópolis,

(...) o olhar destes artistas está voltado para a ilha, seus lugares, seus personagens e ações. É esse mundo que eles vão imortalizar com sua arte, positivando uma cultura cujas bases estão fincadas na cultura açoriana. Procuram dar publicidade a toda sorte de vivência, atitudes e ações que só eram tratadas na esfera do privado e que adquirem valor cultural e político. Temas do cotidiano adquirem status de obra de arte ao serem estetizados e politizados nas palavras dos escritores e no pincel do artista. Um mundo vai sendo tocado e transformado em 'coisas' pela mão do artista que lhe confere imortalidade. (LEHMKUL, 1996, p.39)

O conto "O vigia e a cidade", do artista e ensaísta Hugo Mund Junior, justifica a especificidade modernista catarinense requisitada para olhar a representação da cidade. Projeta a ideia de que esta representação deve ser de uma cidade que "renasce"

\footnotetext{
1 Eduardo Dias (Florianópolis, 1872-1945) pintor, escultor, restaurador, muralista e cenógrafo, frequentou apenas o curso primário. Iniciou sua formação artística com Manoel Francisco das Oliveiras, mas conhecido como Maneca Margarida. Pintou e desenhou diversas obras com motivos de paisagem, cunho religioso e retratos de importantes personagens de sua época. Foi responsável por pintar o teto da igreja Nossa Senhora do Rosário em Florianópolis e realizou alguns relevos escultóricos em prédios públicos da cidade. (BORTOLIN, 2001)
} 
aos olhos do artista, "a cidade impregnada de sua subjetividade, vivência, memória". O tema modernista na capital, baseado na ideia de pertencimento ao local e retorno à fatos da cultura raiz, também girava em torno da tônica das questões de "sensibilidade e subjetividade" (MAKOWIECKY, 2009).

Neste sentido, poucos enxergavam Aldo Beck na direção das rupturas modernas. O próprio se manifesta racionalmente: "meu trabalho é extremamente fiel, eu não fico inventando detalhes...realmente eu retrato a parte física da cidade como ele é ou foi"3. Algumas crônicas e críticas da época revelam o que o espectador poderia encontrar nas obras de Aldo Beck (BECK, s.d.; NEVES, 1968; MELO, 1959; SOARES, 1968), estas relatos, positivos ou negativos, indicam predileções de gosto e ideologias de um período, porém o que está em questão aqui, e que os cronistas desta época não sabiam, é que nada é mais "contemporâneo" em arte do que a estratégia que Aldo Beck adotou: a reinvenção de locais visitados e sublimados, a problemática da memória, da permanência da história, da permanência da imagem. ${ }^{4}$

É na produção de Aldo Beck que vemos perdurar uma fiel predileção pela representação da paisagem de época. $O$ artista parece desacreditar das delirantes projeções do rumo da arte contemporânea de sua época e sem cerimônia se volta ao passado em sua melhor essência, como um fiel servo de sua digressão paisagística. Como um funcionário social da memória visual insinua: "Eu chego a me sentir um pouco responsável pela memória das coisas. É a parte que me cabe. Trabalho em cima do que ainda resta". ${ }^{5}$

Pinta a paisagem que lhe é tão conhecida, porém coloca como objeto central da imagem cenas específicas das quais não presenciou, remetendo a uma ideia quase romântica, como pontuou o icônico artista alemão Caspar David Friedrich em meados de 1800 , como se o pintor de paisagem não devesse pintar somente "o que vê à sua frente, mas também o que vê dentro de si" $^{\prime \prime}$.

Aldo Beck pintou casarios, ruas, pontos emblemáticos da cidade, do comércio e lazer, fazendo assim uma narrativa visual de Florianópolis:

(...) imagens que são fruto de uma escolha que o artista simplifica e organiza, de forma subjetiva, em uma época em que a modernidade se define por um vasto processo de subjetivação do mundo, colocando o espaço imaginário como local de comunicação entre o artista e espectador. (MAKOWIECKY, 2009, p.38)

Na obra "Vista da cidade" (Fig.1), pintada em 1970 por Aldo Beck, vemos a seguinte cena de paisagem urbana: Uma rua, pintada de forma vertical, cruza o meio da pintura até tocar no horizonte da representação, o fundo perspectivo da tela. Nele há o encontro da imagem de uma escadaria que dá acesso a uma igreja e o céu logo a cima,

$5 \quad$ Aldo Beck apud MAKOWIECKY, 2009, p.45.

$6 \quad$ Caspar David Friedrich apud PAGLIA, 2014, p.86. 
centralizando a pequena construção exatamente no meio da imagem. A pequena igreja branca com esquadrias amarelas é o ponto de fuga da imagem e apresenta a representação de uma torre com seu sino à esquerda de sua construção. A rua mencionada está repleta de casas em tom branco; são sobrados representados com um ou dois pavimentos, típicos da arquitetura colonial brasileira, sendo estas concebidas muito próximas umas das outras.

Voltando o olhar pelo plano de fuga da tela, da igreja à via, no plano central da imagem, vemos com destaque três casarões, dois deles localizados nas esquinas desta rua em perspectiva: um em tom rosado à esquerda e outro amarelo à direita. $O$ terceiro casario está localizado também a direita da imagem, em um plano mais à frente da pintura e apresenta um tom azulado. Uma rua horizontalmente representada separa as construções da direita: amarela e azul.

Habitando a imagem, está a representação de diversos micro personagens dispostos pela rua, são quase manchas em quatro tons (blusa, calça, rosto e chapéu), em pequenos aglomerados defronte aos importantes sobrados. Na esquina do casario rosado há a presença de um poste de luz, que a contar pelo seu formato parece não ser gerado por energia elétrica.

Nota-se em toda imagem uma pincelada despojada, que faz movimentos tanto horizontais quanto verticais e pinta as sombras das casa, chão e céu em tons multicoloridos, respeitando a gama da paleta escolhida pelo artista. O céu representado com tons rompidos e cinzas coloridos de verde, azul e roxo, anuncia uma atmosfera densa, parecendo evidenciar uma chuva torrencial que está por vir, típicas das tardes de verão na ilha.

A cena é de um conhecido cruzamento de ruas históricas de Florianópolis: a Rua Conselheiro Mafra e Rua Trajano. A datar pelos trajes dos pequenos personagens com chapéu e bengala, pelos tramados de ferros das sacadas dos sobrados, pelo poste possivelmente gerado a querosene ou a óleo de baleia (BRÜGGEMANN, 2013; MAKOWIECKY, 2008), esta imagem parece apresentar uma cena do final do século XIX.

Nos casarios amarelo e azul, respectivamente, os dizeres que denotam o possível estabelecimento comercial do local: "Casa Fama" e " Casa Oscar Lima", certamente importantes para seu tempo, a contar pela localização na cobiçada e histórica esquina comercial. A rua Conselheiro Mafra, antiga rua do Príncipe e também rua do Comércio, é uma das mais importantes do centro histórico da cidade devido ao intenso comércio estabelecido ali desde 1800. O atual nome da rua foi dado em homenagem ao Conselheiro Manuel da Silva Mafra, ilustre personagem de Santa Catarina (OLIVEIRA, 2012). Ainda hoje essa rua Conselheiro Mafra ostenta belos sobrados herdados de uma cultura comercial portuária existente no local, onde o mar beirava as construções e o mercado público localizado logo ao lado.

Os sobrados típicos do local normalmente abrigavam o estabelecimento comercial em seu piso térreo e a residência da família no piso superior. Por sua arquitetura geminada, os prédios eram providos de pouca iluminação, o que aliado à forte umidade proveniente do mar por diversas vezes apresentavam uma situação um pouco insalubre, como mencionam alguns historiadores (BRÜGGEMANN, 2013).

A igreja ao fundo da imagem se trata da Igreja de Nossa Senhora do Rosário e São Benedito dos Homens Pretos, fundada entre 1787 e 1830 por ex-escravos e 
"homens brancos de espírito humilde". É a segunda igreja mais antiga da região. Ali, importantes artistas acadêmicos catarinenses, como Eduardo Dias e Victor Meirelles, deixaram sua marca artística (GERLACH, 2010; OLIVEIRA, 2012).

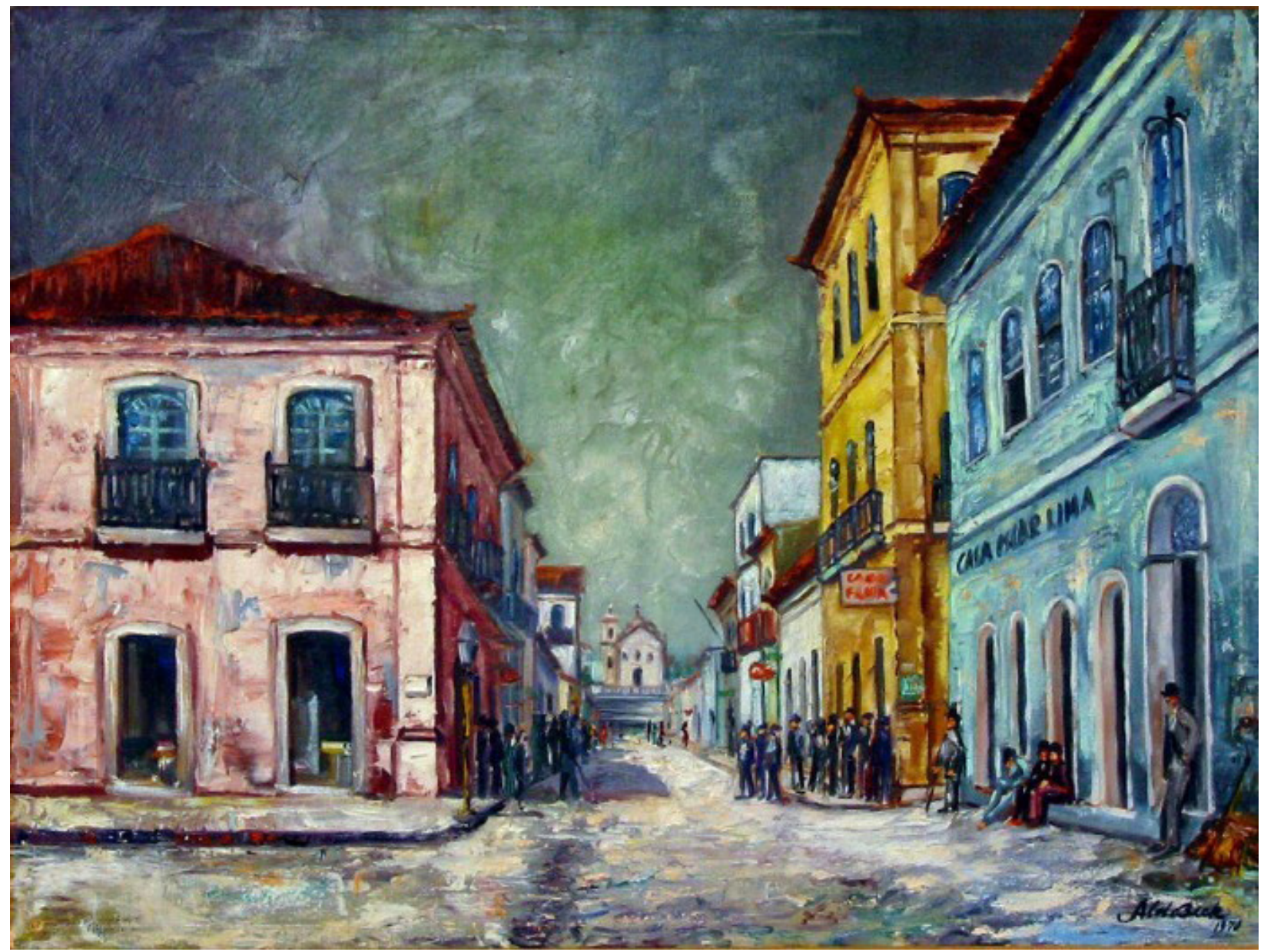

Fig. 1: Aldo Beck. Vista da cidade. 1970. Óleo sobre tela 79x59 cm. Coleção Artur Beck Neto.

Assim como Aldo Beck, Victor Meirelles ${ }^{7}$ teve uma relação intima com a memória paisagística de sua cidade natal: "Victor Meirelles se agiganta com o fato também de ter sido um dos primeiros, se não o primeiro artista brasileiro a eleger a cidade como tema de sua obra e a tratar a cidade como tema"8. Meirelles, natural da ilha de Santa Catarina, antes de seguir incursão pelo mundo para realizar sua produção artística com mais afinco, viveu em um sobrado como os retratados por Aldo Beck, em uma rua que leva hoje o seu nome. Acadêmico nacionalmente reconhecido, Victor Meirelles estabeleceu em sua pintura uma forte ligação estética com a apreensão e observação de sua cidade. Embora tivesse produzido poucas obras especificamente da paisagem de Florianópolis, alguns historiadores afirmam que o artista registrou indiretamente em suas composições a memória familiar de sua ilha (ROSA, 1982; MAKOWIECKY, 2008):

7 (Florianópolis, 1832 - Rio de Janeiro, 1903) “Victor Meirelles de Lima assinou seu nome na história do Brasil através de uma vasta obra pictórica, marcada por uma centena de quadros históricos, retratos e panoramas. Começa a trilhar sua carreira de glórias ainda na primeira metade do século XIX, num momento em que se vive no país a euforia do neoclassicismo, por conta da influência francesa, que mudava os rumos da pintura mundial. Se antes disso o que se fazia tinha um caráter colonial, simplório e sem influência universal, as tintas neoclássicas deram forma e personalidade às artes plásticas nacionais, numa ação que mudou definitivamente conceitos seculares e a imagem brasileira no cenário artístico internacional" (MALLMANN, Regis apud INSITUTO DO PATRIMÔNIO HISTÓRICO E ARTÍSTICO

8 MAKOWIECKY, 2008, p.1 
A paisagem sempre está presente nos quadros históricos que realizou, não obstante, sua vocação espontânea foi para os panoramas, isto é, a paisagem urbana com estudo minucioso de casario, de edificações. $\mathrm{O}$ estruturalismo de suas formas de composição está sempre dentro de um contexto de espaço-paisagem, e desde cedo o ambiente que o cercava o fascinou. As ruas e os casarios ocuparam sua atenção e um caráter histórico descritivo encontra-se em sua pesquisa incansável. (MAKOWIECKY, 2008).

Uma de suas pinturas "Rua João Pinto, antiga Rua Augusta" (Fig. 2) de 1851, representa com fidelidade o tema aqui abordado. Ademais, é uma imagem estruturalmente muito semelhante a tomada de cena de "Vista da Cidade" (Fig. 1) de Aldo Beck.

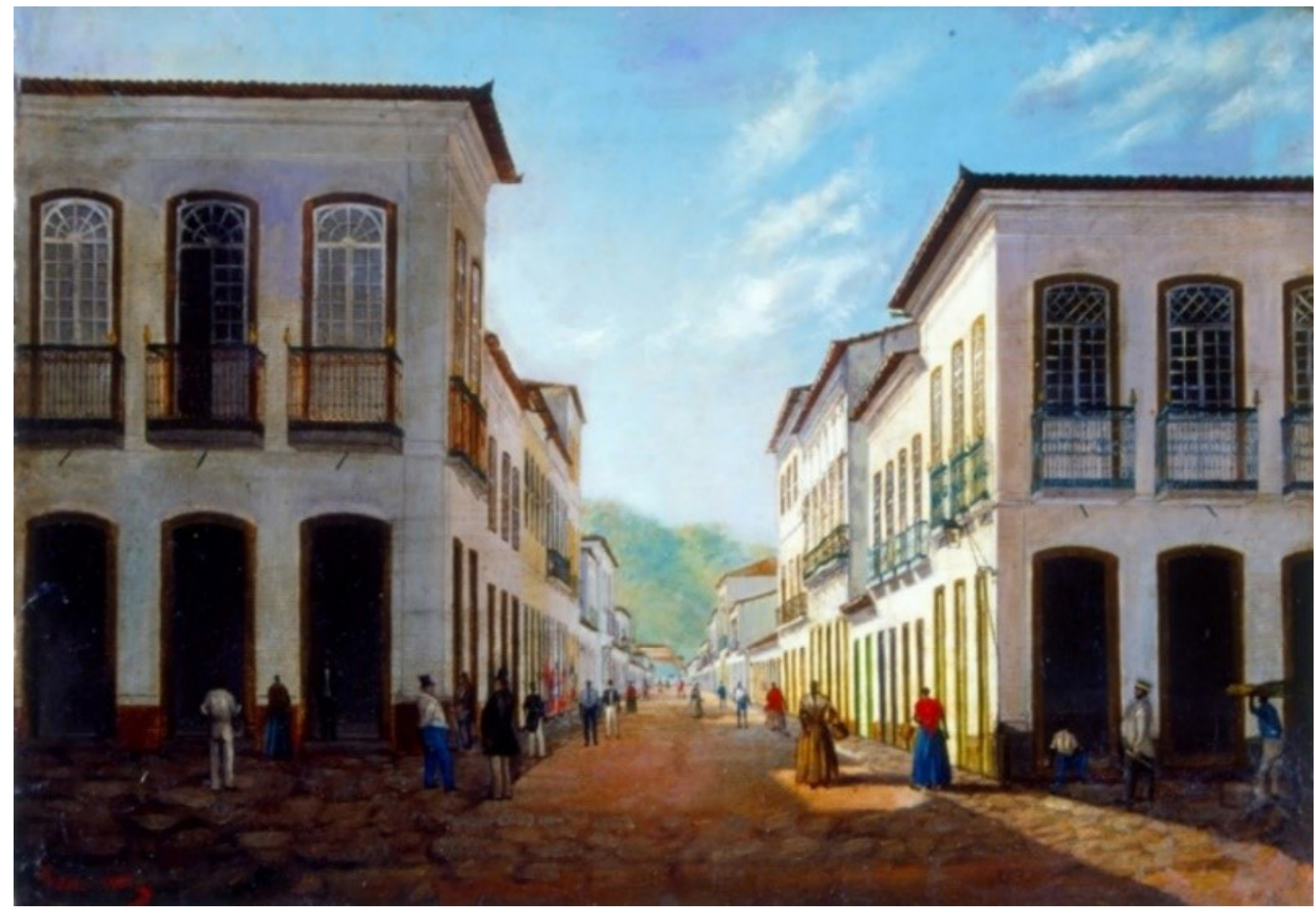

Fig. 2: Victor Meirelles. Rua João Pinto, antiga Rua Augusta, Florianópolis, SC. 1851. Óleo sobre cartão 33,9x49,2 cm. Coleção Museu Nacional de Belas Artes, Rio de Janeiro.

A rua principal em perspectiva, abriga os casarios e sobrados de um e dois andares, geminados. No piso superior das casas, semelhantes sacadas em ferro trabalhado são registradas pelo pintor. Os personagens datam em seus trajes a época. Caminham pela rua em seus afazeres cotidianos e o largo central no primeiro plano da imagem destaca as duas construções nas esquinas que tem suas portas abertas para o possível comércio. O ponto de fuga da imagem não é a igreja de Aldo Beck, mas sim uma adornada montanha verde clara, onde lhe reflete a luz solar e destaca o céu azul com sutis nuvens brancas que parecem estar em movimento. Diferente de Aldo Beck, Victor Meirelles retrata um céu veranil, onde com claridade, refletido em tom amarelado nos sobrados brancos à direita da imagem, destaca uma atmosfera quente e confortante. 
A questão da paleta de cores e emprego do pincel nas duas imagens destaca com evidencia a influência artística e período de confecção das obras. Com afinco, a estrutura e técnica empregada na representação das cores das casas, ruas e principalmente da representação do céu, nos trabalhos dos pintores, diferem e possivelmente confessam a sutileza de como foi a possível observação da cena.

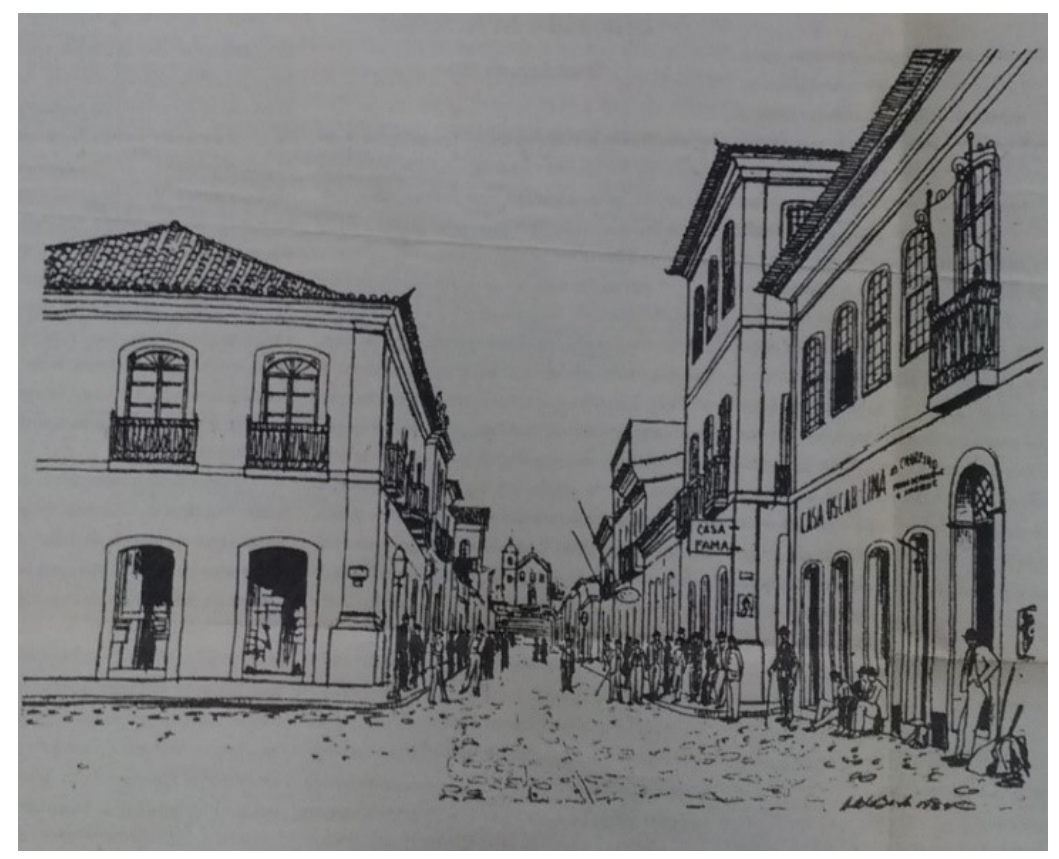

Fig. 3: Aldo Beck. Sem título. 1969? Desenho impresso na revista Ô Catarina na coluna de Osmar Pisani intitulada "Aldo Beck: um autodidata de valor", publicado por ocasião de sua morte em 1999.

Em uma crítica, escrita por Gustavo Neves $^{9}$ em 13 de outubro de 1968 no Jornal $O$ Estado de Florianópolis, por ocasião da segunda exposição individual de Aldo Beck realizada no Hall do Teatro Álvaro de Carvalho em Florianópolis, encontramos os seguintes dizeres:

Nunca será demasiado o amor imenso que Aldo Beck tem por sua Florianópolis. Agora mesmo, com o auxílio de velhas fotos descoloridas e vistas com lente, fica hora a fio debruçado sobre seus quadros, extravasando a alma em espontânea chama de bem querer ao que é nosso. É como vê-lo recriar a cidade dos nossos antepassados, transpondo o tempo para mostrar Florianópolis, ou Desterro, do passado, com suas casas de sacadas de ferro trabalhado, suas ruas ladeadas de postes com lampiões à querosene, os almofadinhas da época, o comércio, a catedral antiga e original, os carrinhos puxados à cavalos e toda uma nostalgia poética artística, transmitida para o atual. (NEVES, 1968)

Neves nos aponta um dado, até então sublimado pela história, sobre o processo de criação adotado por Aldo Beck ao recriar as cenas das quais não presenciou. Com base em "velhas fotos descoloridas" Aldo remonta a história de maneira plástica, através do olhar de outros viventes de sua cidade, capturando e ressignificando o que considera ser a essência de seu local. É como se a Florianópolis de Victor Meirelles fizesse mais sentido aos olhos de Aldo Beck, do que seu próprio momento, quando diante de um progresso urbano de 1949 começa então a produzir. Ele mesmo evi-

$9 \quad$ Gustavo Neves (Florianópolis 1927-2004) foi radioator, produtor, locutor, romancista e jornalista. 
dencia seu método e obsessão: "Eu chego a me sentir um pouco responsável pela memória das coisas. É a parte que me cabe. Trabalho em cima do que ainda resta". ${ }^{10}$

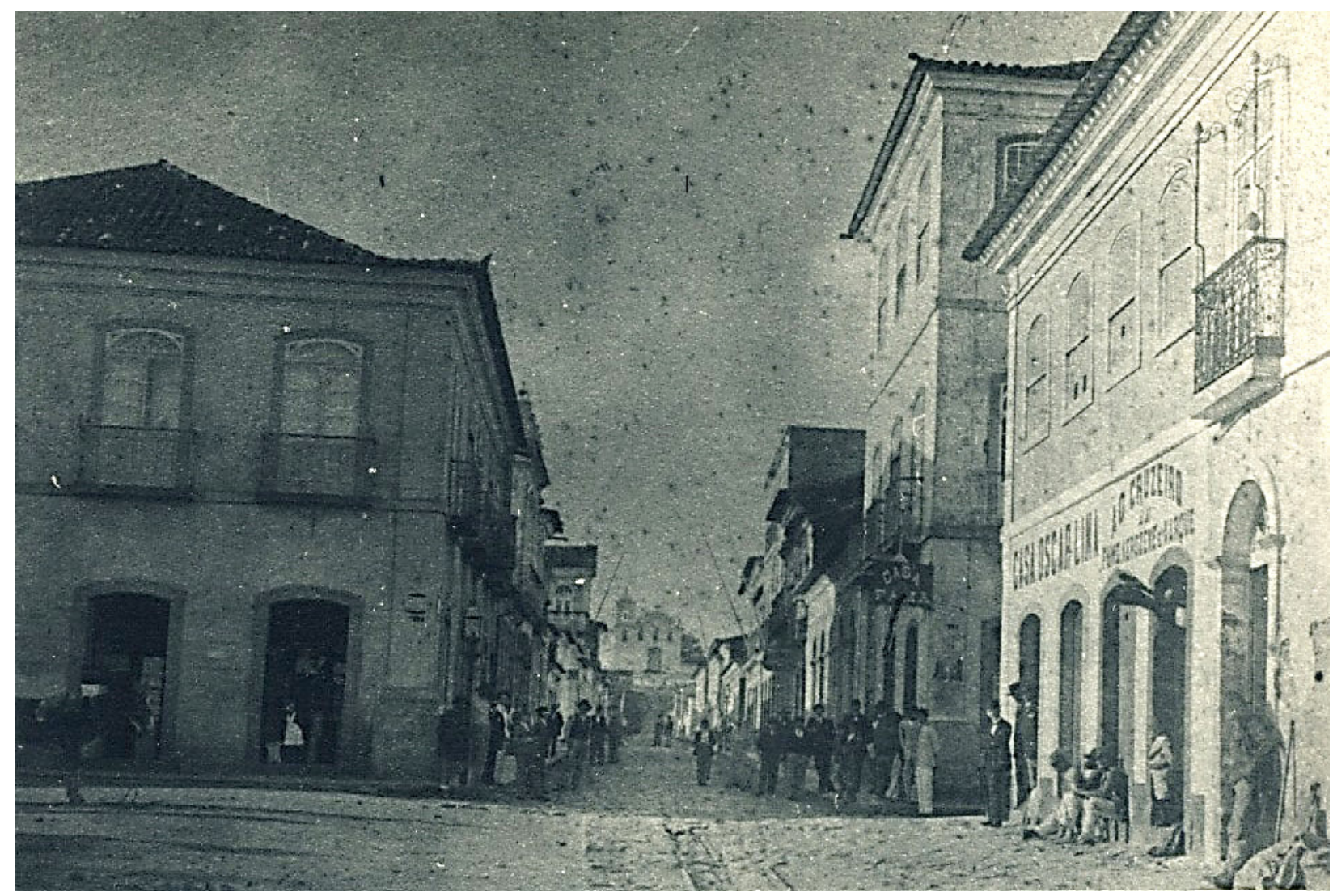

Fig. 4: Rua do Livramento (atual Rua Trajano), esquina com a Rua do Príncipe (atual Rua Conselheiro Mafra), no começo do século XX. Procedência: Família Boiteux. Autor: Canrado Goeldner. Registro da imagem: 1907. Documento digital disponível na Casa da Memória de Florianópolis e Instituto Histórico e Geográfico de Santa Catarina - IHGSC.

É o que lhe incumbe. Incessante trabalho de apropriação e memória.

A fotografia até o século XIX pertencia à condição do registro histórico, do "discurso topográfico da geologia e não ao saber estético, cujo código visual de representação aplainada e comprimida transformou as vistas em paisagens"11. $\mathrm{O}$ estado de pertencimento da fotografia ao campo ou arquivo da arte surge quando ela deixa de ser um mero registro histórico para se inserir no campo estético, sendo na contemporaneidade utilizada como materialidade e dispositivo para produções da obra em seu mais complexo grau.

A exemplo destas complexidades, pensando paralelamente a estratégia de Aldo Beck, a artista contemporânea Rosângela Rennó ${ }^{12}$ representa, com certa ênfase no cenário do circuito artístico atual, a figura que desenvolve de forma elementar a apropriação e utilização da fotografia como dispositivo para a problemática da memória. ${ }^{13}$

\footnotetext{
$10 \quad$ Aldo Beck apud MAKOWIECKY, 2009, p.45.

11 COSTA, 2010, p.83.

12 "Belo Horizonte, 1962. Vive e trabalha no Rio de Janeiro. Formada em arquitetura pela Escola de Arquitetura da Universidade Federal de Minas Gerais, Belo Horizonte (1986) e em artes plásticas pela Escola Guignard, Belo Horizonte (1987). Doutora em artes pela Escola de Comunicações e Artes da Universidade de São Paulo, São Paulo (1997)" Disponível em:< http://www. rosangelarenno.com.br/biografia/pt > Acesso em 24 jul. 2016.

13 Muitos outros artistas contemporâneos fazem utilização desse recurso, de apropriação de fotografias e trabalhos que permeiam uma discussão sobre a questão da memória. Em Florianópolis, como exemplo, vemos proliferar na contemporaneidade alguns representativos artistas que fazem uso destes recursos: Fran Favero, Juliana Hoffmann, Juliana Crispe, Paulo Gaiad, entre outros.
} 
Em sua série "Imemorial" (Fig. 5) de 1994, Rennó coleta imagens em um arquivo público do Distrito Federal e remonta através de cinquenta imagens de trabalhadores "dispensados por motivo de morte", a história da construção de Brasília e sua face mais escura. Ela faz uso das histórias que narram o massacre de dezenas de trabalhadores no processo de construção da capital modelo e que foram enterrados nas estruturas da própria edificação da cidade. Apagados, os personagens tomam novamente corpo na instalação da artista, que tem como tarefa uma incansável busca pela memória.

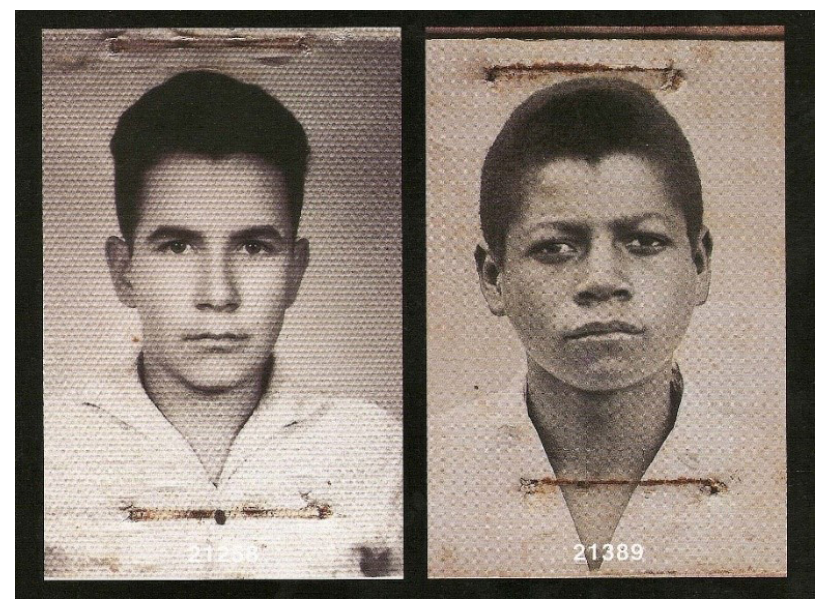

Fig. 5: Fragmento da instalação “Imemorial” de Rosângela Rennó, 1994

$\mathrm{Na}$ instalação "Bibliotheca” (Fig. 6), Rosângela Rennó apresenta novamente a estratégia recorrente em seus trabalhos: a apropriação. Expõe dentro de 37 gabinetes diversos antigos álbuns de fotografia de pessoas comuns. Com sua obra, desperta vários níveis de indagação e ressignifica questões de captura de imagens afetivas e memória: "aspira à condição de um novo arquivo, íntimo e público ao mesmo tempo. As memórias fotográficas de pessoas comuns transformam-se nas memórias comuns a todos"14.

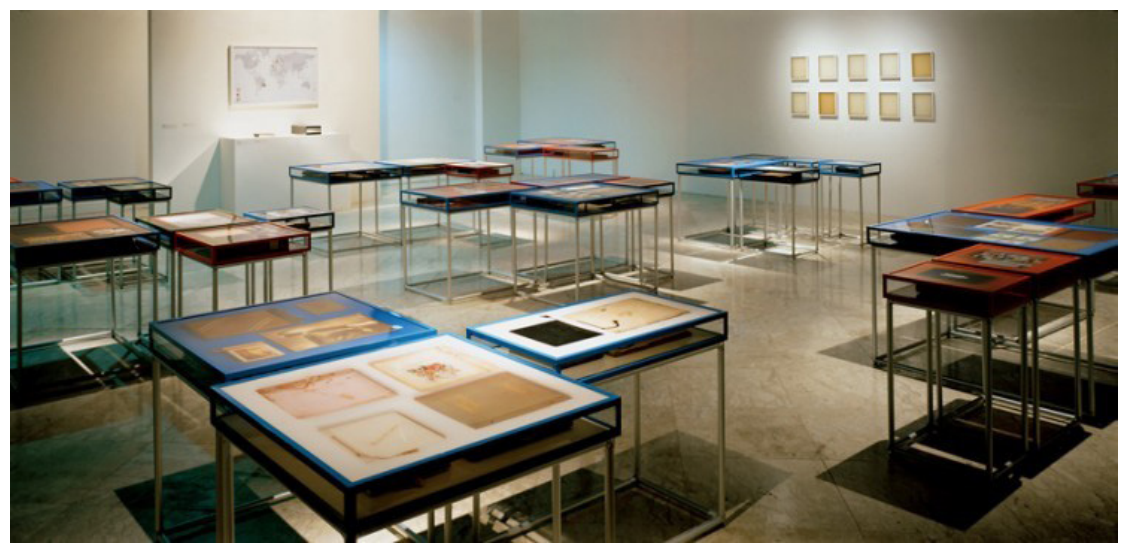

Fig. 6: Fragmento da instalação "Bibliotheca” de Rosângela Rennó, 2002

E porque temos em Didi-Hubermam o perfeito álibi para explicar esta estratégia, podemos afirmar que há no desejo de apropriação, ressignificação e memória algo que parte da imagem esquecida, ou parafraseando sábia expressão do autor: "a imagem arde" (DIDI-HUBERMAM, 2012): 
As noções de memória, montagem e dialética estão aí para indicar que as imagens não são nem imediatas, nem fáceis de entender. Por outro lado, nem sequer estão "no presente", como em geral se crê de forma espontânea. E é justamente por que as imagens não estão "no presente" que são capazes de tornar visíveis as relações de tempo mais complexas que incumbem a memória na história. (DIDI-HUBERMAM, 2012, p. 213)

No texto "Quando as imagens tocam o real" de 2012, o autor trilha de forma primorosa as indagações em torno da questão do aparecimento, desaparecimento e importância da permanência e imanência da imagem. Uma imagem é capaz de reunir em sua essência complexos níveis de interlocução, "deve ser entendida ao mesmo tempo como documento e como objeto de sonho, como obra e objeto de passagem, como monumento e objeto de montagem" (DIDI-HUBERMAM, 2012, p. 209).

Diante dessa estrutura de imagem exposta por Didi-Hubermam, o artista poderia ser entendido como o personagem crucial no desdobramento dessa interlocução. Seria ele o responsável por sentir o "cheiro de fumaça" e nos comunicar, visualmente, sutilmente e de forma poética, por onde esta imagem anda ardendo e que sinais de memória ela apresenta:

Saber olhar uma imagem seria, de certo modo, tornar-se capaz de discernir o lugar onde arde, o lugar onde sua eventual beleza reserva um espaço a um "sinal secreto", uma crise não apaziguada, um sintoma. O lugar onde a cinza não esfriou. (...) Porque a imagem é outra coisa que um simples corte praticado no mundo dos aspectos visíveis. É uma impressão, um rastro, um traço visual do tempo que quis tocar, mas também de outros tempos suplementares - fatalmente anacrônicos, heterogêneos entre eles - que não pode, como arte da memória, não pode aglutinar. É cinza mesclada de vários braseiros, mais ou menos ardentes. (DIDI-HUBERMAM, 2012, p.215-216)

Ou ainda, extraídas as ideias da filosofa alemã Hanna Arendt, a historiadora Luciene Lehmkul concluiu a seguinte frase que nos serve oportunamente: "Portanto, 0 artista aparece como aquele que 'ajuda' o homem que vive a própria história, a imortaliza-la" (LEHMKUL, 1996, p.13).

Isto indica, portanto, a real intenção deste artigo: o "incêndio por vir" através da pintura "Vista da Cidade" (Fig.1) de Aldo Beck. A imagem que ardeu para o artista. A fotografia coletada no arquivo histórico da cidade e olhada com a devida atenção (Fig.4), fez surgir o desejo de imortalizá-la novamente. A contar a data do esboço (Fig.3) de sua possível data de confecção, 1969, constatamos que um ano antes da pintura vir a ser em 1970 (Fig.1) já gerava indícios de latência na vontade do artista.

Se colocamos a imagem fotográfica junto à pintura, podemos ver, indiscutivelmente, a semelhança de construção da estrutura da obra de Aldo Beck. O plano da rua, a massa de personagens espalhadas, a escolha de certas figuras para retratar com precisão, a igreja, o largo, todas estas denotam a base. A pergunta aqui, talvez, deveria ser outra: o que levou Aldo Beck a plasmar essa cena em uma obra? E a resposta deverá ser algo em torno de suposições.

Talvez a Rua João Pinto de Victor Meirelles tenha lhe impregnado a essência e imanência de sua terra natal que tanto quis retratar e ao ver a fotografia lhe despertou a identificação e desejo imediato. Talvez tenha encontrado nas imagens de arquivo um desejo de reviver a época passada. Talvez tenha historicamente alguma relação com a 
imagem proposta. Não saberemos ao certo onde a imagem ardeu em Aldo Beck. Podemos apenas afirmar algumas palavras: Anacronismo, apropriação, ressignificação, desejo de memória. ${ }^{15}$

Ora, seria esta uma estratégia que Aldo Beck adotará para ocasionar o possível rompimento com sua época? Responsabilizando a si próprio o ensejo de perdurar e salvaguardar através de seus quadros a imagem e memória de sua querida cidade, 0 artista representou seu papel de forma incontestável. O trabalho embasado na vontade de memória apontou certamente para um desejo de futuro.

\section{Referências bibliográficas}

BECK, Helena Balkíns. Dados datilografados. Documento disponível na Casa da Memória de Florianópolis. S.d.

BORTOLIN, Nancy Therezinha (Org.). Museu de Arte de Santa Catarina. Biografia de um museu. Itajaí: UNIVALI; Florianópolis: FCC, 2002.

(Org.). Indicador Catarinense das Artes Plásticas. Itajaí: UNIVALI; Florianópolis: Ed.UFSC, FCC, 2001.

BRUGGEMANN, Fábio. História do comércio no Centro Histórico de Florianópolis. Florianópolis: Fecomércio, SC, 2013.

COSTA, Luiz Cláudio da. A poética da memória e o efeito-arquivo no trabalho de Leila Danziger. Revista ARTE \& ENSAIOS 19. PPGAV-EBA-UFRJ, 2010.

DIDI-HUBERMAN, Georges. Quando as imagens tocam o real. Tradução Patrícia Carmello e Vera Casa Nova. Revista Pós: Revista do Programa de Pós-Graduação em Artes da Escola de Belas Artes da UFMG. V. 2. N. 4. Nov. 2012. Disponível em <http://www. eba.ufmg.br/revistapos/index.php/pos/article/view/60> Acesso em 16 jul. 2016.

GERLACH, Gilberto. Desterro: Itha de Santa Catarina. Florianópolis: FCC. 2010.

GUIMARÃES, Andréa Camargo [et al.]. Cronologia de artes plásticas: referências 1975-1995. Centro Cultural São Paulo-IDART: São Paulo, 2010.

INSITUTO DO PATRIMÔNIO HISTÓRICO E ARTÍSTICO NACIONAL. Museu Victor Meirelles - 50 anos; catálogo de obras. Textos Alcídio Mafra de Souza, Daisi Vogel e Regis Mallmann. Apres. Dalmo Vieira Filho e Lourdes Rossetto. Florianópolis: Tempo editorial, 2002.

LEHMKUL, Luciene. Imagens além do círculo. $\mathbf{O}$ grupo de artistas plásticos de

\footnotetext{
15 O termo memória, ou o uso "desejo de memória”, empregado neste artigo diz respeito a vontade de lembrança. Diversos autores trabalharam o conceito de memória. Dos que se aproximam as ideias conectivas com o presente artigo estão Henri Bergson, Marcel Proust e Walter Benjamin. Bergson, situa a memória, ou a lembrança, sem local exato na mente, gerada de forma fragmentada, estabelecida acima de tudo pelo presente incitado. Já a memória para Proust e Benjamin não se trata de um resgate voluntário do passado, mas de um passado que irrompe, que se apossa involuntariamente de nosso presente e de nossos atos.
} 
Florianópolis e a positivação de uma cultura nos anos 50. Florianópolis, UFSC. Dissertação de mestrado, 1996.

MAKOWIECKY, Sandra. Aldo Beck: A narrativa visual de uma cidade e sensibilidade moderna. Anais do XXV Simpósio Nacional de História - ANPUH: Fortaleza, 2009.

; CHEREM, Rosangela Miranda. Academismo e Modernismo em Santa Catarina. 1. ed. Florianópolis: Editora da UDESC, 2010.

O tempo de Victor Meirelles e a Cidade de Florianópolis. 19\&20, Rio de Janeiro, v. III, n. 4, out. 2008. Disponível em: <http://www.dezenovevinte.net/artistas/vm_florianopolis.htm> Acesso em 20 jul. 2016.

MELO, Osvaldo. Nossa Capital. Jornal O Estado de Florianópolis. 16 de maio de 1959. Documento disponível na Casa da Memória de Florianópolis.

NEVES, Gustavo. Prosa de Domingo. Jornal O Estado de Florianópolis. 13 de outubro de 1968. Documento disponível na Casa da Memória de Florianópolis.

OLIVEIRA, Antônio Pereira (Coord.). Roteiro audioguiado do Centro Histórico de Florianópolis. Florianópolis: Câmara de Dirigentes Lojistas - CDL, 2012. Disponível em: <http://www.roteiroautoguiado.com.br> Acesso em 24 jul. 2016.

PAGLIA, Camille. Imagens cintilantes. Uma viagem através da arte, desde o Egito a Star Wars. Rio de Janeiro: Apicuri, 2014.

RENNÓ, Rosângela. Rosângela Rennó: o arquivo universal e outros arquivos. São Paulo: Cosac \& Naify, 2003.

RIBEIRO. Virgínia Cândida. Apropriação na arte contemporânea: colecionismo e memória. Anais do XVII Encontro Nacional da Associação Nacional de Pesquisadores em Artes Plásticas - ANPAP. Florianópolis, 2008.

ROSA, Angelo de Proença e outros. Victor Meirelles de Lima (1832-1903). Prefácio de Alcídio Mafra de Souza. Rio de Janeiro, Pinakoteke, 1982.

SILVA, Adolfo Nicolich da. Ruas de Florianópolis; resenha histórica: Identificação dos agraciados com os nomes das principais avenidas, becos e servidões, situadas na arte insular, somente no perímetro urbano. Florianópolis: Fundação Franklin Cascaes, 1999.

SOARES, Doralécio. Aldo Beck expõe gravuras em novo estilo. Jornal A Gaseta, Floranópolis. 25 de fevereiro de 1968. Documento disponível na Casa da Memória de Florianópolis.

STEGEMANN, Carlos. Memória do Comércio de Florianópolis. Florianópolis: PalavraCom Editora, 2013. 